\title{
No association between the frequency of forest walking and blood pressure levels or the prevalence of hypertension in a cross-sectional study of a Japanese population
}

\author{
Emi Morita $\cdot$ Mariko Naito $\cdot$ Asahi Hishida $\cdot$ \\ Kenji Wakai - Atsuyoshi Mori - Yatami Asai · \\ Rieko Okada $\cdot$ Sayo Kawai $\cdot$ Nobuyuki Hamajima
}

Received: 8 June 2010/ Accepted: 11 November 2010/Published online: 6 January 2011

(C) The Japanese Society for Hygiene 2011

\begin{abstract}
Objective To study the non-temporary effects of successive walks in forested areas (shinrin-yoku) on hypertension prevalence and blood pressure levels.

Methods Data for the analysis were derived from the baseline survey of the Japan Multi-Institutional Collaborative Cohort (J-MICC) study in the Shizuoka area. Eligible participants were individuals aged 35-69 years who attended a health check-up center during 2006 and 2007. Of the 5,040 individuals who participated in the J-MICC study, Shizuoka, 4,666 were included in this analysis [3,174 men and 1,492 women; age (mean \pm standard deviation) $52.1 \pm 8.7$ years]. The frequency of forest walking was estimated by a self-administrated questionnaire. Hypertension was defined as a systolic blood pressure $\geq 140 \mathrm{mmHg}$, a diastolic blood pressure $\geq 90 \mathrm{mmHg}$ or, based on information provided in the questionnaire, the use of medication for hypertension.

Results After adjusting for age, body mass index (BMI), smoking status, alcohol consumption, and habitual exercise, the odds ratios of hypertension associated with forest
\end{abstract}

E. Morita $(\bowtie) \cdot$ M. Naito · A. Hishida - K. Wakai · R. Okada ·

S. Kawai · N. Hamajima

Department of Preventive Medicine,

Nagoya University Graduate School of Medicine,

65 Tsurumai-cho, Showa-ku, Nagoya 466-8550, Japan

e-mail: emorita@med.nagoya-u.ac.jp

A. Mori

Seirei Preventive Health Care Center, Mikatahara-cho,

Kita-ku, Hamamatsu 433-8558, Japan

Y. Asai

Mikatahara Bethel Home,

Seirei Social Welfare Community, 7421-1 Nakagawa,

Hosoe-cho, Hamamatsu 431-1304, Japan walking once a week or more frequently, relative to less than once a month were 0.98 in men $[95 \%$ confidence interval (CI) $0.68-1.42]$ and 1.48 (95\% CI $0.80-2.71)$ in women. There was no significant trend between adjusted blood pressure levels and the frequency of forest walking. Conclusion The results of our cross-sectional study in a Japanese population show no association between either blood pressure levels or the prevalence of hypertension and the frequency of forest walking.

Keywords Forest walking - Shinrin-yoku .

Hypertension · Cross-sectional study $\cdot$ Japanese population

\section{Introduction}

It is empirically accepted that some natural environments contribute to improvements in health. Health resort medicine is included in the medical system in some European countries, with the majority of such health resorts tending to be located in natural environments. Experts in health resort medicine believe that the natural environment of health resorts is a factor that influences the functioning and health of visitors [1]. In this context, the effects of 'green environments' have been reported. In one study, the amount of walkable green space, such as parks and tree-lined streets, around the homes of senior citizens was found to be associated with longevity [2]. An observational study in the UK showed that health inequalities related to income deprivation in all-cause mortality and mortality from circulatory diseases were lower in the greenest areas; in this study, green areas mean green space, including parks, other open spaces, and agricultural land but excluding domestic gardens [3].

Among the activities using green environments that have been promoted as being beneficial to health 
promotion, forest walking, or "shinrin-yoku," is a common leisure activity in Japan. According to a public opinion poll conducted in 2007 by the Cabinet Office of the Government of Japan, $36.2 \%$ of respondents had participated in shinrin-yoku within the preceding year for recreational purposes and mental and physical benefits [4]. However, the effects of forest walking have not been fully elucidated. The temporary acute effects of forest environments have been reported in a number of recent studies. Morita et al. [5] found that hostility and depression scores decreased and liveliness score increased, as measured by the Multiple Mood Scale [6], during a day spent in a forested area compared to that spent in non-forested areas. Natural killer cell activity and immunoglobulin levels have been shown to increase [7] and cortisol and noradrenalin levels to decrease in healthy individuals after a one-off walk in forested areas [8]. A study that evaluated interventions for treating diabetes showed that one-off forest walking was more effective for decreasing blood glucose levels than other forms of exercise, such as cycle ergometer, treadmill, or underwater exercise examined in other studies [9]. In terms of blood pressure, some studies do show that one-off walking in forested areas is significantly effective for temporarily reducing blood pressure compared with walking in non-forested areas [8, 10], although other studies report that there is no significant difference $[7,8,11,12]$.

However, temporary acute effects do not always contribute to improved human health in general. Healthy lifestyles, such as abstinence from smoking, habitual exercise, and non-consumption of alcohol, contribute to the prevention of disease and the maintenance of good health [13-21]. In terms of forest walking, the authors of a crosssectional study reported that the frequency of forest walking was associated with self-rated good general health by the forest walkers [22], suggesting that frequent forest walking may contribute to the maintenance of good health. Based on the reports of positive temporary acute effects of forest environments on reducing blood pressure, frequent forest walking may contribute to the prevention of hypertension. However, there are few studies that have evaluated the non-temporary effects of successive forest walking on blood pressure.

The aim of the study reported here was to investigate the association of the frequency of forest walking with blood pressure levels and the prevalence of hypertension in a Japanese population.

\section{Methods}

Data was derived from the baseline survey of the Japan Multi-Institutional Collaborative Cohort (J-MICC) Study [23] in the Shizuoka area [24]. This was a long-term cohort study to identify interactions between genetics and lifestyle for the prevention of cancer and lifestyle-related diseases [23]. Individuals presenting for health check-ups to the Seirei Preventive Health Care Center in Hamamatsu City, Shizuoka Prefecture, Japan between January 2006 and December 2007 were eligible for enrolment [24]. Criteria for inclusion in the cohort study were an age of between 35 and 69 years and residence in the west-central area of Shizuoka Prefecture, Japan [23, 24]. In total, 13,740 individuals presented for the health check-up who matched the eligibility criteria. Of these, 5,040 (36.7\%) participated in the study [24]. A total of 4,666 participants $\{3,174$ men and 1,492 women; age [mean \pm standard deviation (SD)] $52.1 \pm 8.7$ years $\}$ who responded to a question about their frequency of forest walking were included in this analysis.

The participants were requested to complete a selfadministrated questionnaire that included questions on the frequency of forest walking ( 6 categories: 1 , once a week or more; 2 , two or three times per month; 3 , once a month; 4 , several times a year; 5 , once a year; and 6 , rare) and lifestyle [for example, smoking status, alcohol consumption, and leisure-time activities (intensity, frequency, and duration of exercise]. Participants also on reported whether they had used medication for hypertension, diabetes, high serum cholesterol, or constipation during the preceding month and on their use (if any) of analgesics, sleeping drugs, or other medications.

The blood pressure of each participant was measured once, with the participant in a seated position, using a standard mercury sphygmomanometer with a cuff appropriate for arm size by a nurse during a health check-up. A specific resting time before measurement was not arranged for. Hypertension was defined as a systolic blood pressure (SBP) $\geq 140 \mathrm{mmHg}$, a diastolic blood pressure (DBP) $\geq 90 \mathrm{mmHg}$ or, based on information provided in the questionnaire, the use of medication for hypertension. Optimal blood pressure was defined as SBP $<120 \mathrm{mmHg}$ and DBP $<80 \mathrm{mmHg}$. Normal blood pressure was defined as $\mathrm{SBP}<130 \mathrm{mmHg}$ and $\mathrm{DBP}<85 \mathrm{mmHg}$, but excluding optimal blood pressure. A high-normal blood pressure was defined as SBP $\geq 130 \mathrm{mmHg}$ or $\mathrm{DBP} \geq 85 \mathrm{mmHg}$, and non-hypertension.

Six categories for the frequency of forest walking were summarized into four categories by placing the three less frequent categories (several times a year, once a year, and rare) into one category defined as "less than once a month". Body mass index (BMI) was calculated based on the weight and height of the individual measured at the check-up.

Alcohol consumption was classified into two categories: 1 , once a week or more; 2 , other responses, including "used to drink" and "never drink". Habitual exercise was defined as participating in $\geq 30 \mathrm{~min}$ of a leisure time activity at 
least once a week; the intensity of exercise was not considered.

The associations between ordinal variables were analyzed by the Mantel-Haenszel chi-squared test. The trends in the continuous variables by ordinal categories were tested using a linear regression model. Age-adjusted prevalence of hypertension by frequency of forest walking was calculated by the direct method, and the trend was tested by the Mantel-extension test. Age was categorized into four groups (35-39, 40-49, 50-59, and 60-69 years).

Since the effects of forest walking may be minimal, the age-adjusted association between the frequency of forest walking and blood pressure (4 groups; optimal blood pressure, normal blood pressure, high-normal blood pressure, and hypertension) was also examined. The significance was tested using correlation statistics in the generalized Cochran-Mantel-Haenszel tests.

In logistic regression analysis in Model 1, the dependent variable was hypertension (yes/no); the independent variables were age (continuous variable), frequency of forest walking (4 categories), smoking status (current smokers/ other responses), alcohol consumption (once a week or more/other responses), and BMI ( $\geq 25.0 /<25.0)$. In Model 2, the dependent variable was also hypertension, and the independent variables were the same as in Model 1 plus habitual exercise (yes/no).

The mean values of SBP and DBP by frequency of forest walking were tested using a general liner model (GLM). The following variables were adjusted: (1) age (continuous variable), or (2) age, smoking status (current smokers/other responses), alcohol consumption (once a week or greater/other responses) and BMI $(\geq 25.0 /<25.0)$. The significance level was set at 5\%. PASW Statistics 18 (SPSS, Chicago, IL) and SAS 9.1 (SAS Institute, Cary, NC) were used for the statistical analysis.

The study was approved by the ethics committee of Nagoya University School of Medicine (approval number 288), and written informed consent was obtained from all participants.

\section{Results}

The characteristics of participants by frequency of forest walking are presented in Table 1 . The percentages of each gender in each forest walking frequency group were significantly different (chi-squared test, $p=0.013$ ), with the higher forest walking-frequency groups having a larger percentage of men. A significant trend in mean age was observed in each frequency group among both men (trend $p<0.001$ ) and women (trend $p<0.001$ ), with the higher forest walking-frequency groups associated with a higher mean age. A significant trend was observed between habitual exercise and frequency of forest walking (men: trend $p<0.001$, women: trend $p<0.001$ ), with a higher frequency of forest walking being associated with a greater percentage of participants who engaged in habitual exercise. The percentages of alcohol consumption once a week or more and current smoking in each forest-walking frequency group reached significance in men (alcohol consumption: trend $p<0.001$, current smokers: trend $p=0.002$ ), but not in women (alcohol consumption: trend $p=0.76$, current smokers: trend $p=0.59)$. The percentages of $\mathrm{BMI} \geq 25.0$ by frequency of forest walking were not significant.

The association between the frequency of forest walking and prevalence of hypertension is presented in Fig. 1. A significant trend was observed between the frequency of forest walking and the crude prevalence of hypertension among both men (trend $p<0.001$ ) and women (trend $p=0.004)$. However, the higher walking-frequency groups had a higher percentage of individuals with hypertension. Since age was also associated with the frequency of forest walking, with the higher frequency groups having a higher mean age, age-adjusted prevalence was calculated. No significant trend was found between the ageadjusted prevalence of hypertension and the frequency of forest walking in either men (Mantel-extension test $p=0.25)$ or women $(p=0.23)$.

The association between frequency of forest walking and blood pressure level group by each age subgroup is presented in Table 2. A significant trend was not observed in women (correlation statistics, $p=0.18$ ). A statistical trend was significant in men $(p=0.01)$. However, an obvious trend cannot be identified in Table 2 .

The results of the logistic regression analysis are shown in Table 3. After adjusting for age, BMI, smoking status, and alcohol consumption in Model 1, the frequency of forest walking was not significantly associated with the prevalence of hypertension. The adjusted odds ratios of forest walking once a week or more compared with less than once a month were 0.97 [95\% confidence interval (CI) 0.67-1.40] for men and 1.51 (95\% CI 0.82-2.78) for women. The results show that the frequency of forest walking, including the contribution of habitual exercise, was not associated with the prevalence of hypertension.

In Model 2, when habitual exercise was considered, the frequency of forest walking was again not significantly associated with the prevalence of hypertension. The adjusted odds ratios of the once a week or more groups compared to the less than once a month group were 0.98 (95\% CI 0.68-1.43) for men and 1.43 (95\% CI 0.77-2.65) for women. The results show that the frequency of forest walking, when adjusted for habitual exercise, was not associated with the prevalence of hypertension. 
Table 1 Characteristics of participants by frequency of forest walking

\begin{tabular}{|c|c|c|c|c|c|c|c|c|c|c|}
\hline \multirow[t]{2}{*}{$\begin{array}{l}\text { Frequency of } \\
\text { forest walking }\end{array}$} & \multicolumn{2}{|c|}{$\begin{array}{l}\text { Once a week } \\
\text { or more }\end{array}$} & \multicolumn{2}{|c|}{$\begin{array}{l}\text { Two or three times } \\
\text { per month }\end{array}$} & \multicolumn{2}{|c|}{ Once a month } & \multicolumn{2}{|c|}{$\begin{array}{l}\text { Less than } \\
\text { once a month }\end{array}$} & \multirow{2}{*}{$\begin{array}{l}\text { Total } \\
n\end{array}$} & \multirow[t]{2}{*}{$p$ value } \\
\hline & $n$ & $\%$ & $n$ & $\%$ & $n$ & $\%$ & $n$ & $\%$ & & \\
\hline Total & 235 & 5.0 & 274 & 5.9 & 394 & 8.4 & 3,763 & 80.6 & 4,666 & \\
\hline \multicolumn{11}{|l|}{ Sex } \\
\hline Men & 164 & 5.2 & 210 & 6.6 & 270 & 8.5 & 2,530 & 79.7 & 3,174 & \multirow[t]{2}{*}{$p=0.013^{*}$} \\
\hline Women & 71 & 4.8 & 64 & 4.3 & 124 & 8.3 & 1,233 & 82.6 & 1,492 & \\
\hline \multicolumn{11}{|c|}{ Age $($ mean \pm SD) } \\
\hline Men & \multicolumn{2}{|c|}{$57.3 \pm 7.8$} & \multicolumn{2}{|c|}{$56.8 \pm 8.1$} & \multicolumn{2}{|c|}{$54.7 \pm 8.4$} & \multicolumn{2}{|c|}{$51.7 \pm 8.6$} & $52.6 \pm 8.7$ & Trend $p<0.001^{\dagger}$ \\
\hline Women & \multicolumn{2}{|c|}{$55.5 \pm 7.4$} & \multicolumn{2}{|c|}{$53.7 \pm 8.4$} & \multicolumn{2}{|c|}{$53.7 \pm 8.9$} & \multicolumn{2}{|c|}{$50.4 \pm 8.5$} & $51.0 \pm 8.6$ & Trend $p<0.001^{\dagger}$ \\
\hline \multicolumn{11}{|l|}{$\mathrm{BMI}^{\mathrm{a}} \geq 25.0$} \\
\hline Men & 39 & 23.8 & 52 & 24.8 & 62 & 23.0 & 662 & 26.2 & & Trend $p=0.31^{*}$ \\
\hline Women & 8 & 11.3 & 13 & 20.3 & 18 & 14.5 & 202 & 16.4 & & Trend $p=0.51^{*}$ \\
\hline \multicolumn{11}{|c|}{ Alcohol consumption ${ }^{\mathrm{b}}$} \\
\hline Men & 126 & 77.3 & 158 & 76.0 & 179 & 66.8 & 1,666 & 66.2 & & Trend $p<0.001^{\ddagger}$ \\
\hline Women & 18 & 26.1 & 16 & 25.0 & 42 & 34.1 & 325 & 26.5 & & Trend $p=0.76^{*}$ \\
\hline \multicolumn{11}{|c|}{ Current smokers $^{\mathrm{c}}$} \\
\hline Men & 35 & 21.3 & 33 & 15.7 & 47 & 17.5 & 631 & 25.0 & & Trend $p=0.002^{*}$ \\
\hline Women & 2 & 2.8 & 2 & 3.1 & 7 & 5.7 & 54 & 4.4 & & Trend $p=0.59^{*}$ \\
\hline \multicolumn{11}{|c|}{ Habitual exercise ${ }^{\mathrm{d}}$} \\
\hline Men & 129 & 79.1 & 144 & 68.6 & 167 & 62.1 & 1,207 & 48.1 & & Trend $p<0.001^{*}$ \\
\hline Women & 54 & 77.1 & 45 & 75.0 & 80 & 66.1 & 530 & 43.5 & & Trend $p<0.001^{*}$ \\
\hline \multicolumn{11}{|c|}{ Chi-squared test; ${ }^{\dagger}$ linear regression model; ${ }^{*}$ Mantel-Haenszel chi-squared test } \\
\hline \multicolumn{11}{|c|}{ Body mass index; number of available responses was 4,665 (men: $n=3,173$, women: $n=1,492$ ) } \\
\hline \multicolumn{11}{|c|}{ b Once a week or more; number of available responses was 4,636 (men: $n=3,155$, women: $n=1,481$ ) } \\
\hline c Number of a & lable & onses & 4,657 & $n=3,17$ & omen: & 1,487 & & & & \\
\hline
\end{tabular}

Since blood pressure levels are affected by hypertension medications, blood pressure levels by frequency of forest walking were stratified for medication use (see Table 4). A significant trend in the crude blood pressure levels by frequency of forest walking was partially observed, with the higher forest walking-frequency groups having higher mean blood pressure values. However, these trends disappeared when the data were adjusted for age, alcohol consumption, smoking status, and habitual exercise.

\section{Discussion}

This study revealed that the frequency of forest walking was not associated with either blood pressure levels or the prevalence of hypertension. Furthermore, there were no observed associations between the frequency of forest walking and blood pressure levels with respect to obesity (BMI $\geq 25.0 /<25.0$ ), and diabetes (positive or negative) after adjustment for age, smoking status, alcohol consumption, habitual exercise, and medication for hypertension using GLM (data not shown). However, in the subgroup of women without dyslipidemia, the association of SBP with frequency of forest walking was significant after adjustment for the above-mentioned factors (data not shown). In the subgroups of men with dyslipidemia and women without dyslipidemia, the associations of DBP with frequency of forest walking were also significant (data not shown). Nevertheless, neither a trend of crude SDP by frequency of forest walking in the subgroup of women without dyslipidemia nor trends of crude DBP by frequency of forest walking in subgroups of men with dyslipidemia and women without dyslipidemia were observed using linear regression models for the trend test (data not shown). Although the beneficial temporary acute effects of one-off forest walking on reducing blood pressure have been previously reported $[8,10]$, our results suggest that frequent forest walking does not have any non-temporary effects on blood pressure. 


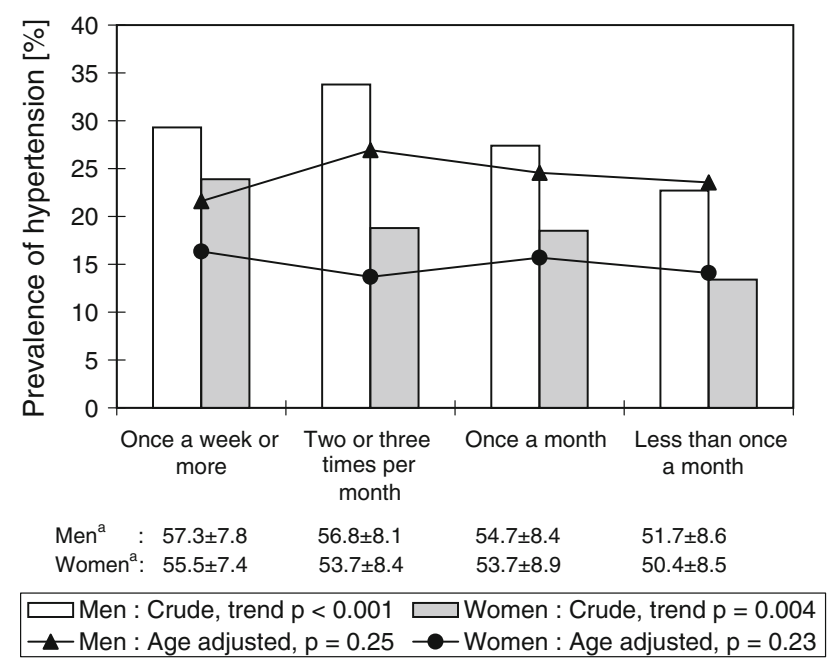

Fig. 1 Crude and age-adjusted prevalence of hypertension by each forest walking-frequency group. Age-adjusted prevalence was calculated by the direct method. Age was categorized into four groups (35-39, 40-49, 50-59, and 60-69 years). Trend was tested by the MantelHaenszel chi-squared test in crude. The age-adjusted trend was calculated by the Mantel-extension test. ${ }^{\mathrm{a}}$ Mean age \pm standard deviation (SD)

It should be noted that some studies have reported that the mean values of SBP and DSP after forest walking were not significantly different from those after walking in city areas [11] or from those among healthy students in an indoor setting [7]. Another study reported that the mean reduction in DBP was not significantly different between individuals walking in a forested area and those walking in a non-forested area [8].

These results show an inconsistency in the temporary acute effects of one-off forest walking on decreasing blood pressure, suggesting that the acute beneficial effects of forest walking in terms of decreasing blood pressure are weak or absent. Although some studies have reported that blood pressure decreased significantly by walking in forested areas compared with non-forested areas, the difference in the mean values of blood pressure reported was less than $3-16.5 \mathrm{mmHg}[8,10]$. This difference may be within the normal range of daily fluctuations in blood pressure. As a consequence, the non-temporary effects may not be shown.

The other possible explanation for the lack of an association between the frequency of forest walking with either blood pressure levels or the prevalence of hypertension is that more frequent forest walking may be required to improve hypertension or to maintain optimal/normal blood pressure. The category for frequency of forest walking with the most responses in our study was once a week or more. This level of "once a week or more" may not have reached

Table 2 The association between frequency of forest walking and blood pressure level group by each age subgroup

\begin{tabular}{|c|c|c|c|c|c|c|c|c|}
\hline \multirow[t]{2}{*}{ Blood pressure } & \multicolumn{2}{|c|}{ Once a week or more } & \multicolumn{2}{|c|}{ Two or three times per month } & \multicolumn{2}{|c|}{ Once a month } & \multicolumn{2}{|c|}{ Less than once a month } \\
\hline & $n$ & $\%$ & $n$ & $\%$ & $n$ & $\%$ & $n$ & $\%$ \\
\hline \multicolumn{9}{|l|}{ Men } \\
\hline \multicolumn{9}{|l|}{ 30-39 (years) } \\
\hline Optimal & 3 & 100.0 & 5 & 62.5 & 7 & 53.8 & 137 & 60.1 \\
\hline Normal & 0 & 0.0 & 2 & 25.0 & 5 & 38.5 & 55 & 24.1 \\
\hline High-normal & 0 & 0.0 & 1 & 12.5 & 0 & 0.0 & 23 & 10.1 \\
\hline Hypertension & 0 & 0.0 & 0 & 0.0 & 1 & 7.7 & 13 & 5.7 \\
\hline \multicolumn{9}{|l|}{ 40-49 (years) } \\
\hline Optimal & 19 & 63.3 & 17 & 53.1 & 27 & 43.5 & 408 & 50.2 \\
\hline Normal & 4 & 13.3 & 5 & 15.6 & 10 & 16.1 & 168 & 20.7 \\
\hline High-normal & 4 & 13.3 & 6 & 18.8 & 18 & 29.0 & 106 & 13.0 \\
\hline Hypertension & 3 & 10.0 & 4 & 12.5 & 7 & 11.3 & 131 & 16.1 \\
\hline \multicolumn{9}{|l|}{ 50-59 (years) } \\
\hline Optimal & 16 & 27.1 & 27 & 31.4 & 41 & 36.0 & 383 & 38.8 \\
\hline Normal & 17 & 28.8 & 13 & 15.1 & 24 & 21.1 & 201 & 20.4 \\
\hline High-normal & 14 & 23.7 & 20 & 23.3 & 20 & 17.5 & 153 & 15.5 \\
\hline Hypertension & 12 & 20.3 & 26 & 30.2 & 29 & 25.4 & 250 & 25.3 \\
\hline \multicolumn{9}{|l|}{ 60-69 (years) } \\
\hline Optimal & 18 & 25.0 & 11 & 13.1 & 15 & 18.5 & 142 & 28.3 \\
\hline Normal & 9 & 12.5 & 14 & 16.7 & 10 & 12.3 & 102 & 20.3 \\
\hline High-normal & 12 & 16.7 & 18 & 21.4 & 19 & 23.5 & 77 & 15.3 \\
\hline Hypertension & 33 & 45.8 & 41 & 48.8 & 37 & 45.7 & 181 & 36.1 \\
\hline
\end{tabular}


Table 2 continued

\begin{tabular}{|c|c|c|c|c|c|c|c|c|}
\hline \multirow[t]{2}{*}{ Blood pressure } & \multicolumn{2}{|c|}{ Once a week or more } & \multicolumn{2}{|c|}{ Two or three times per month } & \multicolumn{2}{|c|}{ Once a month } & \multicolumn{2}{|c|}{ Less than once a month } \\
\hline & $n$ & $\%$ & $n$ & $\%$ & $n$ & $\%$ & $n$ & $\%$ \\
\hline \multicolumn{9}{|l|}{ Women } \\
\hline \multicolumn{9}{|l|}{ 30-39 (years) } \\
\hline Optimal & 1 & 100.0 & 6 & 66.7 & 10 & 90.9 & 144 & 86.2 \\
\hline Normal & 0 & 0.0 & 2 & 22.2 & 1 & 9.1 & 14 & 8.4 \\
\hline High-normal & 0 & 0.0 & 1 & 11.1 & 0 & 0.0 & 5 & 3.0 \\
\hline Hypertension & 0 & 0.0 & 0 & 0.0 & 0 & 0.0 & 4 & 2.4 \\
\hline \multicolumn{9}{|l|}{ 40-49 (years) } \\
\hline Optimal & 9 & 69.2 & 3 & 60.0 & 22 & 75.9 & 298 & 72.9 \\
\hline Normal & 0 & 0.0 & 1 & 20.0 & 2 & 6.9 & 53 & 13.0 \\
\hline High-normal & 4 & 30.8 & 1 & 20.0 & 1 & 3.4 & 30 & 7.3 \\
\hline Hypertension & 0 & 0.0 & 0 & 0.0 & 4 & 13.8 & 28 & 6.8 \\
\hline \multicolumn{9}{|l|}{ 50-59 (years) } \\
\hline Optimal & 20 & 54.1 & 19 & 54.3 & 25 & 56.8 & 259 & 54.6 \\
\hline Normal & 6 & 16.2 & 5 & 14.3 & 7 & 15.9 & 78 & 16.5 \\
\hline High-normal & 3 & 8.1 & 4 & 11.4 & 5 & 11.4 & 58 & 12.2 \\
\hline Hypertension & 8 & 21.6 & 7 & 20.0 & 7 & 15.9 & 79 & 16.7 \\
\hline \multicolumn{9}{|l|}{ 60-69 (years) } \\
\hline Optimal & 4 & 20.0 & 5 & 33.3 & 18 & 45.0 & 71 & 38.8 \\
\hline Normal & 4 & 20.0 & 2 & 13.3 & 8 & 20.0 & 30 & 16.4 \\
\hline High-normal & 3 & 15.0 & 3 & 20.0 & 2 & 5.0 & 28 & 15.3 \\
\hline Hypertension & 9 & 45.0 & 5 & 33.3 & 12 & 30.0 & 54 & 29.5 \\
\hline
\end{tabular}

Correlation statistics in the generalized Cochran-Mantel-Haenszel tests (for men) $p=0.01$; correlation statistics in the generalized CochranMantel-Haenszel tests (for women) $p=0.18$

Table 3 The adjusted odds ratio for prevalence of hypertension

\begin{tabular}{|c|c|c|c|c|}
\hline \multirow[t]{2}{*}{ Model } & \multicolumn{2}{|l|}{ Men } & \multicolumn{2}{|c|}{ Women } \\
\hline & $\mathrm{aOR}$ & $95 \% \mathrm{CI}$ & $\mathrm{aOR}$ & $95 \% \mathrm{CI}$ \\
\hline \multicolumn{5}{|l|}{ Model $1^{\mathrm{a}}$} \\
\hline \multicolumn{5}{|l|}{ Frequency of forest walking } \\
\hline Less than once a month & 1 & & 1 & \\
\hline Once a month & 1.07 & $0.79-1.44$ & 1.02 & $0.60-1.71$ \\
\hline Two or three times per month & 1.19 & $0.86-1.64$ & 1.07 & $0.54-2.12$ \\
\hline Once a week or more & 0.97 & $0.67-1.40$ & 1.51 & $0.82-2.78$ \\
\hline \multicolumn{5}{|l|}{ Model $2^{\mathrm{b}}$} \\
\hline \multicolumn{5}{|l|}{ Frequency of forest walking } \\
\hline Less than once a month & 1 & & 1 & \\
\hline Once a month & 1.08 & $0.80-1.47$ & 1.04 & $0.61-1.75$ \\
\hline Two or three times per month & 1.21 & $0.87-1.67$ & 0.88 & $0.42-1.84$ \\
\hline Once a week or more & 0.98 & $0.68-1.43$ & 1.43 & $0.77-2.65$ \\
\hline
\end{tabular}

aOR, Adjusted odds ratio; CI, confidence interval

a Adjusted by age(continuous valuable), BMI ( $\geq 25.0 /<25.0)$, smoking status (current smokers/other responses), and alcohol consumption (once a week or more/other responses)

b Adjusted by age (continuous valuable), BMI ( $\geq 25.0 /<25.0$ ), smoking status (current smokers/other responses), alcohol consumption (once a week or more/other responses), and habitual exercise (leisure time activity: $\geq 30$ min exercise at least once a week) 
Table 4 Blood pressure levels by frequency of forest walking

\begin{tabular}{|c|c|c|c|c|c|c|c|c|c|c|c|}
\hline \multirow[t]{2}{*}{$\begin{array}{l}\text { Frequency of } \\
\text { forest walking }\end{array}$} & \multicolumn{2}{|c|}{$\begin{array}{l}\text { Once a week } \\
\text { or more }\end{array}$} & \multicolumn{2}{|c|}{$\begin{array}{l}\text { Two or three times } \\
\text { per month }\end{array}$} & \multicolumn{2}{|c|}{ Once a month } & \multicolumn{2}{|c|}{$\begin{array}{l}\text { Less than once } \\
\text { a month }\end{array}$} & \multirow[t]{2}{*}{$\begin{array}{l}\text { Trend } \\
p^{\dagger}\end{array}$} & \multirow[t]{2}{*}{$\begin{array}{l}\text { Adjusted }^{\mathrm{a}} \\
p^{\ddagger}\end{array}$} & \multirow[t]{2}{*}{$\begin{array}{l}\text { Adjusted }^{\mathrm{b}} \\
p^{*}\end{array}$} \\
\hline & $n$ & Mean $\pm \mathrm{SD}$ & $n$ & Mean $\pm \mathrm{SD}$ & $n$ & Mean $\pm \mathrm{SD}$ & $n$ & Mean $\pm \mathrm{SD}$ & & & \\
\hline \multicolumn{12}{|c|}{ Systolic blood pressure } \\
\hline \multicolumn{12}{|l|}{ Men } \\
\hline \multicolumn{12}{|c|}{ Medication for hypertension } \\
\hline- & 139 & $122.5 \pm 16.5$ & 165 & $122.9 \pm 16.0$ & 220 & $121.0 \pm 14.5$ & 2211 & $118.4 \pm 14.5$ & $<0.001$ & 0.03 & 0.69 \\
\hline+ & 25 & $133.3 \pm 12.0$ & 45 & $129.3 \pm 13.6$ & 50 & $134.7 \pm 12.7$ & 319 & $131.2 \pm 13.1$ & 0.72 & 0.19 & 0.50 \\
\hline \multicolumn{12}{|l|}{ Women } \\
\hline \multicolumn{12}{|c|}{ Medication for hypertension } \\
\hline- & 60 & $117.3 \pm 14.8$ & 55 & $114.6 \pm 13.1$ & 111 & $112.3 \pm 15.6$ & 1121 & $112.0 \pm 14.7$ & 0.005 & 0.28 & 0.17 \\
\hline+ & 11 & $136.5 \pm 18.0$ & 9 & $132.2 \pm 17.8$ & 13 & $130.6 \pm 16.0$ & 112 & $131.2 \pm 14.2$ & 0.32 & 0.73 & 0.78 \\
\hline \multicolumn{12}{|c|}{ Diastolic blood pressure } \\
\hline \multicolumn{12}{|l|}{ Men } \\
\hline \multicolumn{12}{|c|}{ Medication for hypertension } \\
\hline- & 139 & $75.8 \pm 10.2$ & 165 & $76.9 \pm 10.7$ & 220 & $75.4 \pm 10.5$ & 2211 & $75.3 \pm 10.3$ & 0.13 & 0.65 & 0.62 \\
\hline+ & 25 & $78.7 \pm 8.8$ & 45 & $80.0 \pm 8.0$ & 50 & $82.4 \pm 7.2$ & 319 & $82.1 \pm 9.7$ & 0.04 & 0.75 & 0.49 \\
\hline \multicolumn{12}{|l|}{ Women } \\
\hline \multicolumn{12}{|c|}{ Medication for hypertension } \\
\hline- & 60 & $72.3 \pm 8.2$ & 55 & $70.0 \pm 10.2$ & 111 & $68.2 \pm 9.6$ & 1121 & $68.6 \pm 9.8$ & 0.008 & 0.10 & 0.36 \\
\hline+ & 11 & $81.8 \pm 15.8$ & 9 & $78.9 \pm 9.5$ & 13 & $80.5 \pm 11.9$ & 112 & $78.9 \pm 9.7$ & 0.42 & 0.65 & 0.87 \\
\hline
\end{tabular}

${ }^{\dagger}$ Linear regression model; ${ }^{*}$ General linear model

a Adjusted by age(continuous variable)

b Adjusted by age(continuous valuable), body mass index (BMI) ( $\geq 25.0 /<25.0)$, smoking status (current smokers/other responses), alcohol consumption (once a week or more/other responses), and habitual exercise (leisure time activity: once a week for at least 30 min or more/other responses)

the threshold required for the improvement of blood pressure or maintenance of optimal/normal blood pressure.

There are a number of limitations associated with our study. (1) This was a cross-sectional study and as such could not identify a causal relationship. This lack of an association between the frequency of forest walking and blood pressure levels/hypertension prevalence may be caused by those forest walkers with hypertension who had just begun forest walking to improve their hypertension. Cohort studies or intervention studies will be required to confirm this lack of association. (2) The study participants may not represent the general population in Japan because they attended private health check-ups that involved high expenses; these participants may be more interested in health promotion activities than the general population. The percentage of current smokers in the study cohort was $23.3 \%$ for men and $4.4 \%$ for women [24]. These percentages are lower than for the general population in Japan [25]. (3) We evaluated the non-temporary effects of successive forest walking based solely on the frequency of forest walking. Duration may contribute to the non-temporary effects of successive forest walking on blood pressure, although acute psychological effects have been reported not to depend on the duration of forest waking [6]. (4) Blood pressure measurements were conducted only once.

In conclusion, the results of our current cross-sectional study in a Japanese population showed no association between either blood pressure levels or the prevalence of hypertension and the frequency of forest walking.

Acknowledgments This study was supported by a Grant-in-Aid for Scientific Research on Special Priority Areas of Cancer from the Ministry of Education, Culture, Sports, Science and Technology, Japan. The authors declare that they have no conflicts of interest.

\section{References}

1. Morita E, Weigl M, Schuh A, Stucki G. Identification of relevant ICF categories for indication, intervention planning and evaluation of health resort programs: a Delphi exercise. Int J Biometeorol. 2006;50:183-91.

2. Takano T, Nakamura K, Watanabe M. Urban residential environments and senior citizens' longevity in megacity areas: the importance of walkable green spaces. J Epidemiol Community Health. 2002;56:913-8. 
3. Mitchell R, Popham F. Effect of exposure to natural environment on health inequalities: an observational population study. Lancet. 2008;372:1655-60.

4. Cabinet Office of Government of Japan. The opinion poll on forests and life 2007 (in Japanese). Tokyo: Cabinet Office of Government of Japan; 2007.

5. Morita E, Fukuda S, Nagano J, et al. Psychological effects of forest environments on healthy adults: Shinrin-yoku (forest-air bathing, walking) as a possible method of stress reduction. Public Health. 2007;121:54-63.

6. Terasaki M, Kishimoto Y, Koga A. Construction of a multiple mood scale (in Japanese). Shinrigaku Kenkyu. 1992;62:350-6.

7. Ohira H, Takagi S, Masui K, Oishi M, Obata A. Effects of shinrin-yoku (forest-air bathing and walking) on mental and physical health (in Japanese). Tokai Jushi-daigaku Kiyo. 1999;19:217-32.

8. Shimomura Y. Effect of forest on health (in Japanese). Ningen Shokubutsu Kankei Gakkai Zasshi. 2002;1:11-4.

9. Ohtsuka Y, Yabunaka N, Takayama S. Shinrin-yoku (forest-air bathing and walking) effectively decreases blood glucose levels in diabetic patients. Int J Biometeorol. 1998;41:125-7.

10. Park BJ, Tsunetsugu Y, Kasetani T, Kagawa T, Miyazaki Y. The physiological effects of Shinrin-yoku (taking in the forest atmosphere or forest bathing): evidence from field experiments in 24 forests across Japan. Environ Health Prev Med. 2010;15:18-26.

11. Tsunetsugu Y, Park BJ, Ishii H, Hirano H, Kagawa T, Miyazaki Y. Physiological effects of Shinrin-yoku (taking in the atmosphere of the forest) in an old-growth broadleaf forest in Yamagata Prefecture, Japan. J Physiol Anthropol. 2007;26:135-42.

12. Kozaki T, Ishibashi K, Horinouchi K, Noguchi J, Hashitomi K, Yasukouchi K. Effects of basking in the forest on physiological responses (in Japanese). Jpn J Biometeorol. 2007;44:105-10.

13. Belloc NB, Breslow L. Relationship of physical health status and health practices. Prev Med. 1972;1:409-21.

14. Belloc NB. Relationship of health practices and mortality. Prev Med. 1973;2:67-81.

15. Metzner HL, Carman WJ, House J. Health practices, risk factors, and chronic disease in Tecumseh. Prev Med. 1983;12:491-507.
16. Kusaka Y, Kondou H, Morimoto K. Healthy lifestyles are associated with higher natural killer cell activity. Prev Med. 1992;21:602-15.

17. Ezoe S, Morimoto K. Behavioral lifestyle and mental health status of japanese factory workers. Prev Med. 1994;23:98-105.

18. Seki A, Takigawa T, Ito T, Fukuoka E, Takahashi K, Kira S. Obesity and the risk of diabetes mellitus in middle-aged Japanese men. Acta Med Okayama. 2002;56:255-60.

19. Ishikawa-Takata K, Ohta T, Moritaki K, Gotou T, Inoue S. Obesity, weight change and risks for hypertension, diabetes and hypercholesterolemia in Japanese men. Eur $\mathbf{J}$ Clin Nutr. 2002;56:601-7.

20. Ando M, Wakai K, Seki N, Tamakoshi A, Suzuki K, Ito Y, et al. Attributable and absolute risk of lung cancer death by smoking status: findings from the Japan Collaborative Cohort Study. Int J Cancer. 2003;105:249-54.

21. Sobue T, Yamamoto S, Hara M, Sasazuki S, Sasaki S, Tsugane S. JPHC Study Group. Japanese Public Health Center. Cigarette smoking and subsequent risk of lung cancer by histologic type in middle-aged Japanese men and women: the JPHC study. Int J Cancer. 2002;99:245-51.

22. Morita E, Nagano J, Fukuda S, Nakashima T, Iwai Y, Yamamoto $\mathrm{H}$, et al. Relationship between forest walking (shinrin-yoku) frequency and self-rated health status: cross-sectional study of healthy Japanese (in Japanese). Jpn J Biometeorol. 2009;46: 99-107.

23. J-MICC Study Group. The Japan Multi-Institutional Collaborative Cohort Study (J-MICC Study) to detect gene-environment interactions for cancer. Asian Pac J Cancer Prev. 2007;8:317-23.

24. Asai Y, Naito M, Suzuki M, Tomoda A, Kuwabara M, Fukada Y, et al. Baseline data of Shizuoka area in the Japan Multi-Institutional Collaborative Cohort Study (J-MICC Study). Nagoya J Med Sci. 2009;71:137-44.

25. Health and Welfare Statistics Association. (4) Tobacco. J Health Welfare Stat. 2008;55:90-3. 